\title{
A Terra é azul
}

\section{Gianni Ratto}

Em seu famoso prefácio à peça Seis personagens em busca de um autor, Pirandello fala de uma criadinha travessa que se diverte a levar para ele, em seu local de trabalho, pessoas, objetos e idéias provocantes a fim de serem aproveitadas, solicitando-o em sua criatividade: a esta criadinha ele deu o nome de Fantasia.

Seis personagens - espetáculo dentro do espetáculo - é realizado num palco vazio, com luz de serviço; o pano de boca está aberto desde o início e quando desce é por descuido do maquinista; a magia das luzes, um clima quase ritualístico, o surgimento de um pedaço de cenário, um golpe de cena (a aparição de Madama Pace) são resultados não de maquinismos ou de tecnologia, mas fruto de uma intuição poética que cria lírica e malabaristicamente climas e milagres pela simples força evocativa da palavra.

Em Nossa cidade, de Thorton Wilder, o palco não somente está vazio como os objetos necessários para a ação são definidos e materializados pela mímica dos atores, enquanto, cordialmente, a personagem do diretor descreve os cenários e sua colocação.

No Sonho de uma noite de verão de Shakespeare (ato $3^{\circ}-$ cena $1^{a}$ ), enquanto Titania permanece adormecida, entram os Clowns, Lecoing, Etriqué, Bottom, Flute, Groin e Meurt de Faim que discutem a montagem de Pyramo e Thisbe e os problemas técnicos relacionados a cenários, luz, etc.:

“LECOING - ... mas ainda temos de resolver dois problemas difíceis: trazer o luar para um dos quartos; pois como sabeis, Pyramo e Thisbe se encontram à luz da lua.

ETRIQUÉ - Será que a lua vai brilhar na noite do espetáculo?

BOTTOM - Um calendário! um calendário! Olhem no almanaque: encontrem o luar, encontrem o luar!

LECOING - Sim, a lua estará brilhando naquela noite!

BOTTOM - Então você poderá deixar aberta uma parte da clarabóia na grande sala onde estaremos representando, e a lua poderá entrar.

LECOING - Sim, ou então alguém poderia aparecer carregando um feixe de gravetos e uma lanterna dizendo que veio para representar a personagem da lua. Mas há o segundo problema: precisamos ter um muro na grande sala; porque Pyramo e Thisbe, segundo a história, conversavam pela fresta de uma parede.

ETRIQUÉ - Nunca vocês conseguirão transportar um muro até a sala; que acha disto Bottom?

BOTTOM - Alguém deverá representar o muro: Será necessário que em suas roupas sejam colocados reboque, argila ou cal; e também que ele mantenha o braço horizontal com a mão fechada mas com o indicador e o médio abertos em V: assim Pyramo e Thisbe falarão pela abertura.

LECOING - Se isso for possível, então está tudo bem. E agora, seus filhos

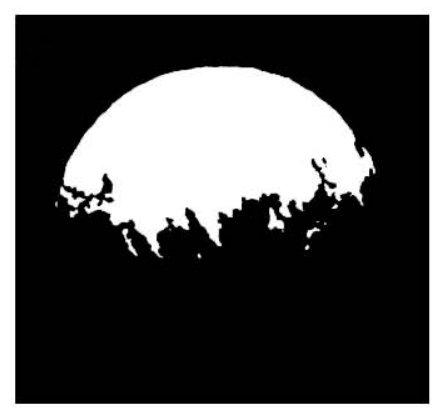

GIANNI RATTO é diretor de cenografia, tendo colaborado em diversas montagens de companhias teatrais nacionais e do exterior. Durante dois anos foi professor da ECA-USP e, atualmente, está preparando um livro sobre o ofício de cenógrafo. 
de mães honradas, sentem-se e comecem a ensaiar seus papéis."

O teatro da Renascença resolvia seus problemas com três cenários fixos, construídos, básicos: o "trágico", o "cômico" e o "pastoral".

O teatro elisabetano valia-se de uma estrutura fixa articulada em dois planos; o texto, quando necessário, pedia ao público que visse um exército lá onde estava um só comediante ou, então, a lua, quando um homem acompanhado por um cachorro passasse no palco carregando uma lanterna.

Assim também, o despojamento é total no "curral" espanhol, nos teatros orientais, nos espetáculos de praça, nas missas das igrejas românicas. Assim é, enfim, em toda representação que exige uma participação interiormente ativa e que, portanto, possa dispensar cenários e maquinárias.

Os exemplos são inúmeros e sempre coincidem com os mais altos momentos da poesia dramática, contemporânea ou do passado.

O aproveitamento de técnicas alheias à estrutura física do edifíco teatral vem de longe. As embarcações gregas forneceram guindastes, moitões, cordalhas, para a realização de efeitos cênicos indispensáveis à aparição de deuses, à revelação horripilante e catártica dos cadáveres das personagens assassinadas. Engrenagens simples mas eficazes permitiam rodar elementos cênicos, revelando novos espaços, e telões desciam ou voltavam a subir assim como as velas de um navio eram manobradas: o uso de prismas triangulares (periactos), vôos e cenários deslizantes, de engenhos para efeitos acústicos e visuais era a conseqüência inevitável da presença mágica dos deuses e do destino que eles determinavam para o homem. Eram os poetas que pediam isso; o que era procurado não era o efeito pelo efeito e sim um meio que, sem extrapolar a essência do momento dramático, se constituísse em algo tão forte e importante quanto o gesto de Medéia.

A perfeita execução dos efeitos era de certo menos importante do que suas resultantes dramáticas; não duvido que o espectador visse somente o que sua participação emocional lhe sugeria; sua visão subjetiva apagava a eventual deficiência de mecanismos indisfarçáveis e a queda de um Ícaro (relatada por Suetónio, século I d.C.), por exemplo, não devia perturbar sua expectativa cega, ansiosa e participante.

O homem da Idade Média é responsável, perante Deus, por seus próprios atos e pensamentos, e não mais escravo de um destino determinado pelos deuses. $O$ conceito de "milagre", que pode subverter beneficamente um acontecimento trágico ou representar um "mistério" inexplicável, é traduzido em termos de dramaturgia na forma da representação medieval. O "milagre" e o "mistério" passam a ser elementos, produtos oferecidos a um público realmente faminto e consumidor de grandes efeitos sugestivos, promissores de prêmios ou castigos, com a presença alucinante ou onírica de demônios asquerosos ou anjos assexuados, com a execução de pecados carnais explícitos ou com a compadecida apresentação da Paixão de Cristo. Para tanto, engenheiros, arquitetos, criadores de mecanismos e autômatos, mágicos, carpinteiros e eclesiásticos perspicazes oferecem ao teatro - servidos entusiasticamente por comunidades inteiras - seus inventos, descobertas e conseqüentes aplicações, tanto no interior das igrejas como nas ruas ou nas praças.

Giorgio Vasari, o grande biógrafo de artistas plásticos e arquitetos (século XVI), atribui a Filippo Brunelleschi (1377-1446) o projeto e a execução de uma "maquinária" realizada em Florença para a Festa da Anunciação. Vale a pena ler o seu relato:

“... havia portanto o Brunellesco arrumado as coisas de tal maneira que se via, no alto, um céu repleto de figuras vivas, movimentando-se, e uma infinidade de lumes que, quase num instante, apareciam e desapareciam. Doze crianças, vestidas de anjos, com asas douradas e cabeleiras de ouro, seguravam-se pelas mãos e, agitando os braços, davam a sensação de estar dançando. Acima de suas cabeças, havia três grinaldas de luzes, situadas dentro de pequenas lamparinas que, vistas do chão, pareciam estrelas, e as prateleiras que as sustentavam, cobertas por tufos de algodão, davam a ilusão de nuvens. Mais outras oito crianças, situadas numa plataforma menor, desciam no meio das primeiras, sem impedir sua visibilidade, lentamente, por meio de um pequeno guindaste. Sempre do alto e no mesmo eixo, movida por engenhos mecânicos, descia uma estrutura em forma de amêndoa, luminosa, colocada no centro das duas outras armaçōes. Nesta "amêndoa", um mocinho de uns quinze anos, vestido de anjo, seguro na cintura por meio de um aro de 


\section{2}

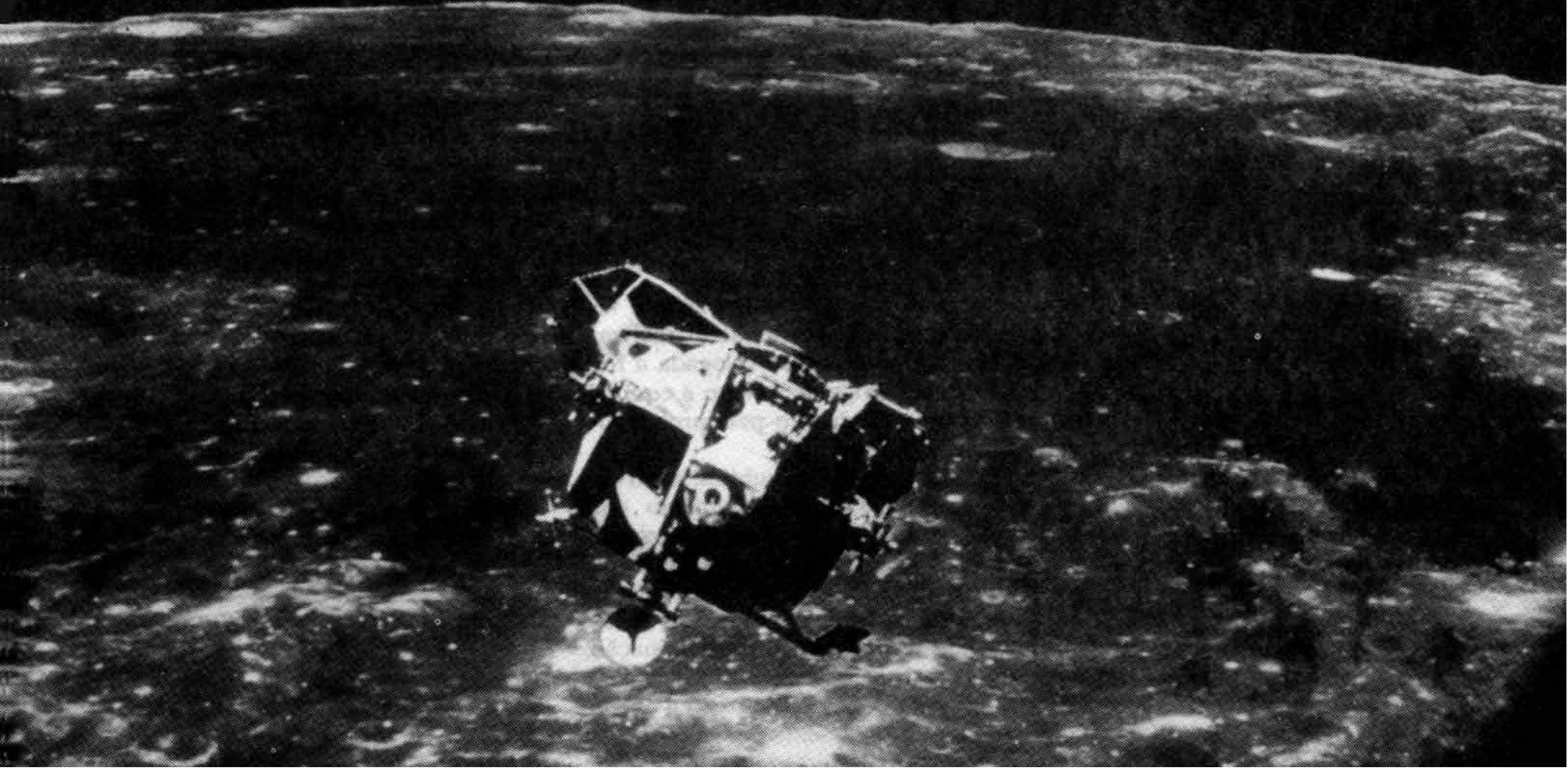

ferro fixado ao chão para evitar que ele caísse, podia se ajoelhar por ser este ferro articulado. E quando a "amêndoa" pousava sobre um patamar de quatro degraus, o dito ferro destravava-se permitindo ao anjo sair e dirigir-se à Virgem, saudando-a e levando a Ela o Anúncio. Em seguida, o anjo voltava à sua "amêndoa" que acendia novamente suas luzes e iniciava sua subida enquanto, cantando, voltavam a subir os oito meninos da plataforma intermediária e os quinze anjos dourados rodavam dando ao conjunto a sensação exata de um paraíso; tanto mais que além desses anjos todos havia também um Deus Pai, rodeado de outros anjos, parecidos com os outros, também amarrados na cintura, de tal maneira que o céu, os meninos, Deus Pai e a "amêndoa", com seus inúmeros lumes e suavíssimas músicas, representavam o paraíso de verdade. Acrescente-se a tudo isso que, para poder aquele céu abrir-se e fechar-se, Filippo havia mandado executar duas grandes portas que, se abrindo, puxavam cordalhas que provocavam ruídos de trovoadas e, quando fechadas, abrigavam materiais necessários à representação."

Equivalentemente importante e fastuoso foi o Apparato per le nozze di Francesco $d e^{\prime}$ Medici, projetado por Leonardo da Vinci e também relatado pelo Vasari, no qual todas as inovações tecnológicas estavam presentes, com a realização de efeitos luminosos e a simultaneidade de múltiplos movimentos por meio de um único mecanismo.

Maquinárias e efeitos grandiloqüentes foram características do teatro religioso medieval, da Renascença e do Barroco (grandes bailados mitológicos e esplendorosas cenografias onde a aplicação da perspectiva reinava) e, mais tarde, nos espetáculos de opera e no teatro naturalista - sem falar das salas especializadas onde a pseudomagia se aliava às mais recentes aquisiçōes tecnológicas.

A cápsula espacial, com os astronautas Armstrong e Aldrin a bordo, deixa o solo lunar para 0 reencontro com o módulo de comando pilotado por Collins, a fim de darem inicio à viagem de regresso à Terra, que aparece ao fundo 


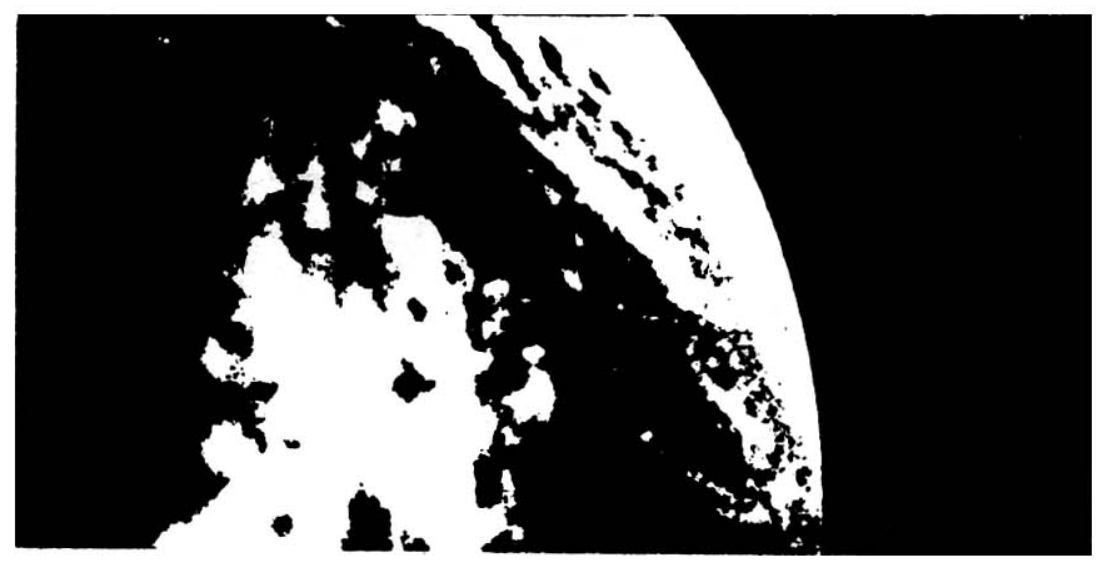

Encantar, sugestionar e "enganar" constituem portanto um fenômeno permanente que transcende a verdadeira essência do teatro e de sua dramaturgia, cujas características básicas são as idéias e a poesia.

Inganni. Assim eram chamados os aparatos cênicos baseados em mudanças rápidas e na aplicação rigorosa e criativa da perspectiva à pintura dos cenários que substitúam triunfalmente as pesadas construçōes fixas renascentistas. Com o único movimento manual - de muitos homens, claro - de um enorme tambor de madeira, por meio de cordas, roldanas, moitōes e carretilhas, conseguia-se acionar um palco inteiro, em todos os seus setores, despertando a surpresa e o encantamento de espectadores cada vez mais famintos da magia do visual que coreografia e cenografia conseguiam realizar. Onde estava agora a crédula fé da Idade Média? Para onde tinha sido relegada a força dos mitos da antiga Grécia? O consumismo visual era tão exigente quanto a equivalência emocional despertada hoje nas classes de menor poder adquisitivo pela propaganda televisiva.

Em 1638, Nicola Sabbatini publica um livro fundamental para o desenvolvimento das técnicas de palco: Prattica di fabbricare scene e macchine. Este tratado, verdadeira obra-prima de percepção, antecipadora de conquistas futuras, ensinava a colorir, reduzir e aumentar a intensidade da iluminação (naquele tempo basicamente a óleo), movimentar no palco um navio em meio a ondas revoltas; mudar rapidamente um cenário (de um mágico jardim mitológico para um faustoso palácio senhorial, por exemplo, sem que o público se desse conta de como isto tinha acontecido. (Sugeria, por exemplo, que no fundo da platéia alguém desse um toque de corneta, ou um tiro de pistola, ou fingisse o estourar de uma briga, obrigando os espectadores a se virarem para

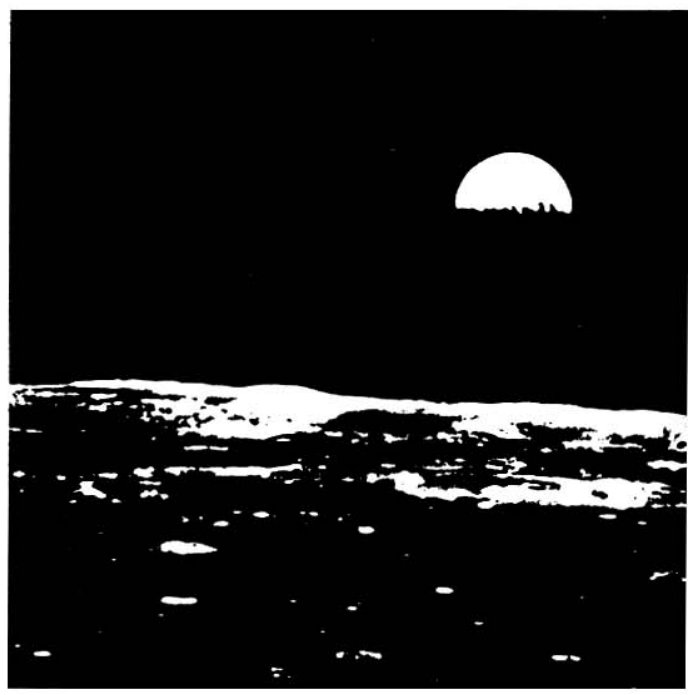
que, quando voltassem a olhar o palco, encontrassem a fantástica e inexplicável mudança satisfatoriamente realizada.)

Sem dúvida alguma a cenografia e suas técnicas seguem o caminho das conquistas da revolução industrial e das linguagens estéticas. Se durante muito tempo ela é o resultado de intuiçōes e pesquisas de artistas e artesãos, com o decorrer do tempo servirá cada vez mais em profundidade às propostas dos teóricos que, desde a segunda metade do século XIX, irão revolucionar a linguagem visual e dramatúrgica na busca de uma integração cada vez mais profunda.

Todavia, o progresso e a evolução da tecnologia em todos os setores do espetáculo, a conquista de novos e inconceb́fveis potenciais luminosos (gás, primeiro, eletricidade e eletrônica, depois) aliados a formas de controles cada vez mais sofisticados, provocam e alimentam a fome de efeitos mais complexos e, tamberm, como aconteceu com Appia e Gordon Craig, a formulação de um discurso positivamente subversivo.

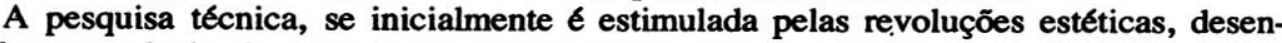
volve-se todavia de uma forma extemporânea e independente de qualquer teoria, na maioria dos casos preocupada em oferecer equipamentos cada vez mais aperfeiçoados quer no setor da iluminação, quer no da engenharia mecânica dos palcos, que se utiliza da hidráulica, da eletrônica, dos comandos a distância, do raio laser, da holografia, da computação e de tudo o que pertence às conquistas da "última geração". Em alguns casos, com Svoboda ou Moholi Nagui, a indústria segue uma informação mais correta, mas, com eles - e foi o proprio Svoboda que me disse isto -, a preocupação era agilizar 
os aparatos técnicos em função de uma maior pureza de linguagem.

O cinema e a televisão, com suas técnicas cada vez mais arrojadas, necessitam realmente serem assistidos por um instrumental que, pode se dizer, é sistematicamente superado pelo próximo invento. Mas quando o teatro esquece suas origens e finalidades, tentando concorrer com meios de expressão antitéticos, destina-se ao naufrágio. Este raciocínio não elimina a necessidade que determinados espetáculos líricos e coreográficos têm de equipamentos e aparelhagens tecnicamente perfeitos: a Tetralogia de Wagner, a Flauta mágica de Mozart, As indias galantes de Rameau, o Sadko ou A lenda da cidade invistvel de R. Korsakov, o Excelsior de L. Manzotti, o Nabuco de Verdi - só para citar algumas obras entre tantas - não poderiam ser convenientemente realizadas se não dispusessem de palcos maleáveis e adequadamente equipados (alçapões, pontes hidráulicas, urdimentos motorizados, carros telecomandados, giratórios cilíndricos, etc.), com áreas e cubagens de seis a doze vezes superiores ao espaço efetivo de utilização prática e visual. O edifício teatral se transforma numa verdadeira usina tecnológica e computadorizada que, assim como um navio de guerra, tem seus engenheiros, comandantes, oficiais e subalternos: o Teatro de Goteborg, na Suécia, teve sua mecânica realizada pelos estaleiros navais bélicos. Aliás, nada de novo no front: já vimos que a dramaturgia grega tinha encontrado seus recursos técnicos justamente nas manobras das velas de seus navios.

Nosso século assiste à transformação radical do edifício teatral. Muitas salas de espetáculo continuam ainda sendo projetadas e constrúdas segundo os cânones tradicionais do teatro "à italiana", que subordina o espaço dedicado ao público ao respeito rigoroso das hierarquias sociais em detrimento de qualquer critério de perfeita visibilidade.

O "ponto de vista do rei", princípio básico de toda a perspectiva cenográfica, identifica um único eixo visual lá onde o "príncipe", o "duque" ou o "rei" estarão sentados ao lado de suas nobres esposas: e os outros que se danem. Este critério predominará, durante alguns séculos, na projetação da cenografia teatral, persistindo em sobreviver até os dias de hoje em espetáculos de características tradicionais e nos ateliers produtores de cenografias de aluguel.

O conceito de um ponto de vista idêntico para todos, de uma acústica perfeita em todos os setores da sala - se se constitui num reencontro feliz com as formas mais antigas da arquitetura teatral - é fruto também da preocupação de permitir que a "obra" seja salvaguardada para todos em sua total integridade estética. Não se trata, parece-me, de uma conquista social (em muitos casos, pelo menos) que respeita todos os níveis culturais e econômicos, mas de um nivelamento a favor de uma comunicação coletiva: numa divertida reviravolta, o espetáculo assume a posição do "príncipe", passando a ser o centro do interesse coletivo.

Falei "em muitos casos", não num fenômeno generalizado. No decorrer deste século (desde, aliás, 1876, com a sala do Teatro Wagneriano de Bayreuth - projeto de Bruckwald) as propostas, muitas vezes sadias e agressivamente revolucionárias, foram inúmeras e na maioria dos casos interessantes e válidas. Norman Bel Geddes, Gropius, De Pero, Moholi Nagui, Vatchangoff, etc. procuraram incorporar o palco à platéia numa riqueza de propostas planimétricas e situacionais (a presença de Piscator

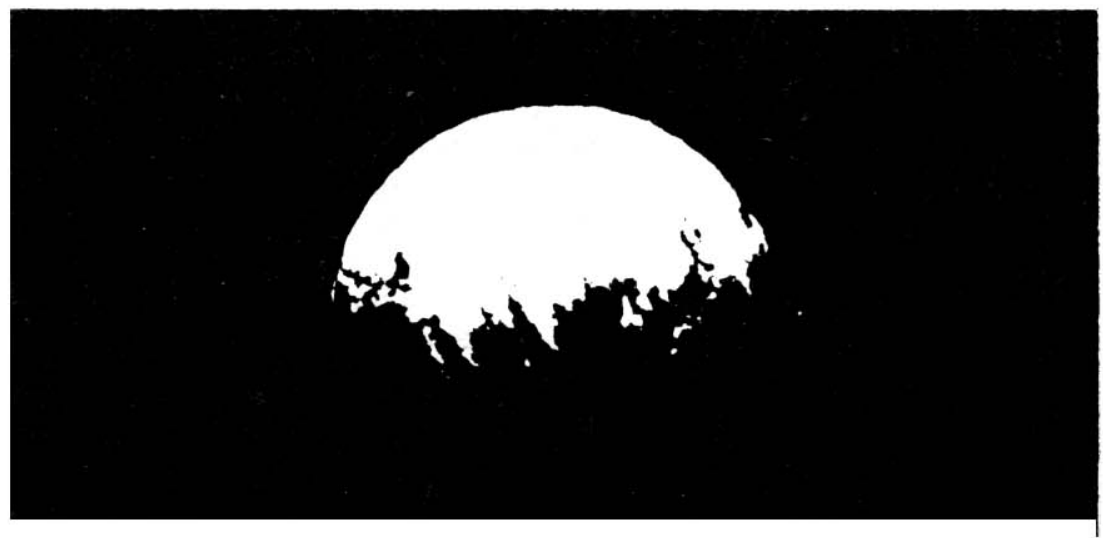

-

Setembro

Outubro

Novembro 
e Brecht, de Meyerhold, etc. é criativamente provocadora), preocupados com a projetação de edifícios versáteis, de estruturas polivalentes, que visam situar o espectador num envolvimento que rompe com qualquer convencionalidade emocional, movimentando-o numa espacialidade cinética ou situando-o no eixo dinâmico e vertical de uma estrutura esférica. $O$ edifício teatral acolhe e seleciona todos os recursos que a tecnologia - e sua pesquisa constante - oferece-lhe de mão cheia. Os projetos de Polieri, Venturelli, Werner Ruhnau, André Bloc são verdadeiros delírios criativos, vôos interespaciais pelo universo teatral, na tentativa de alcançar novos planetas, novas galáxias.

Mas não sei não; já fiz muitos espetáculos amaldiçoando palcos desprovidos de convenientes equipamentos técnicos; já montei cenários em palcos ultraequipados onde tudo era possível menos conseguir um azul mediterrâneo indispensável a uma cenografia de commedia dell'arte. Já fiquei fascinado por um inesperado resultado, casualmente apagando todas as luzes do palco (que eram poucas) e vendo o meu espaço iluminado pelos vergalhões fantomáticos projetados por uma única lâmpada pendurada acima do urdimento, balançando sozinha, pesadelo alucinante de um fim de peça ionesquiano.

Não será certamente eu que depois de ter assistido à magia da ida a Kittesh num palco em que a seqüência cenográfica nada tinha a dever a outras, e mais amparadas, técnicas de linguagem visual; não será certamente eu que, tendo tido a oportunidade de participar da execução da tempestade do $1^{\circ}$ ato de Otelo de Verdi, numa montagem do Teatro Alla Scala - dirigida por Nicolas Benois - para a execução da qual foram necessárias mais de 120 pessoas; não será certamente eu que negará a importância de um teatro plenamente equipado e de uma pesquisa cada vez mais aprofundada para a conquista de tecnologias que permitam delírios criativos somente superados por "viagens psicodélicas". Não nego nada, mas não posso deixar de constatar que nenhum motor conseguirá, para um passeio bucólico, substituir uma leve caleche puxada por um garboso cavalo branco. Não é surpreendente que na era das viagens interplanetárias, dos mísseis e dos satélites, uma das mais maravilhosas invenções da atualidade seja a da asa delta que propicia ao novo Ícaro a reconquista do silêncio perdido?

Não sei não, mas se o teatro não é basicamente um ato de amor, um ato de fé, não sei mais o que é teatro. Se a palavra "poeta" perdeu seu sentido, se a entrega de si mesmo tem de ser amparada por pára-quedas e escafandros, se tudo o que é autenticamente simples não é mais suficiente, então é melhor que o teatro feche suas portas e venda seus equipamentos como sucata a preço de banana.

Continuo acreditando (como sempre acreditei, independendo das traições às minhas convicçōes) num teatro despojado, pobre - até andrajoso - onde tudo seja ritual, espontâneo, num contexto de signos e símbolos. Acredito na juta que, pela luz de uma vela, se transforma em preciosíssimo brocado; acredito no galho de árvore que é cajado, cetro e serpente: um tudo que muda pelo olhar mágico de um gato. A humanidade precisa de poesia e não de teatro com "gosto artificial de poesia". A humanidade precisa de meios para entrar em contato consigo mesma; precisa poder gritar de angústia, de desejo, de ódio e de prazer, sem que seus gritos fiquem abafados por holofotes e ruídos de engrenagens; precisa reencontrar seus espaços, suas luminosidades, suas decepções; reencontrar a compreensão de seus destinos.

Creio que a humanidade está cansada de teorias, métodos e técnicas, neste século composto de muitos séculos; penso que ela ainda acredita na "palavra", que anseia por um novo "verbo" e que não está mais muito disposta a um tipo de informação ligada basicamente ao consumismo e às conveniências de seus governantes. Acho que a única voz de um novo "poeta" seria ouvida e recebida como um hóspede especialmente querido e longamente esperado.

A importância da tecnologia é inegável, mas ela não apaga nem resolve a agonia de um planeta em evidente extinção, que se autodevora com uma inconsciência delirante.

De resto, se quisermos ficar aqui no Brasil, onde os teatros, na maioria dos casos, não passam de carcaças antidiluvianas, carroçarias desmanteladas, arcabouços desmoronantes, não é evidente que a dramaturgia e a arte do espetáculo sobreviveram graças à presença criadora de autores, atores e poetas preocupados com o que estavam dizendo, independendo das condições técnicas e políticas desfavoráveis?

A pergunta surge inevitável: um texto de Carlos Drummond de Andrade teria mais valor, seria mais "belo" se fosse impresso com uma técnica holográfica?

Pelo que lembro, Armstrong, quando desceu na Lua, não falou do fantástico comportamento tecnológico de sua engenhoca espacial. Se não estou enganado, ele disse: "A Terra é azul!". 